\title{
Comparisons of NBS/Harvard VI Simulations and Full-Scale, Multiroom Fire Test Data
}

\author{
JOHN A. ROCKETT* \\ Consultant \\ Washington, DC 20016-2041, USA
}

\author{
MASAHIRO MORITA \\ Department of Applied Mathematics \\ Tokyo Science University \\ Tokyo, Japan
}

\author{
LEONARD Y. COOPER \\ Center for Fire Research \\ US National Bureau of Standards \\ Gaithersburg, Maryland 20899, USA
}

ABSTRACT

The NBS/Harvard VI multi-room fire model was used to simulate results of previously reported full-scale multi-room fire experiments. The tests and simulations involved: four different compartment configurations of two or three rooms connected by open doorways, four different fire types generated by a methane burner and up to four different doorway openings between the burn room and adjacent space. A total of nineteen different tests were carried out and simulated. Selected comparisons between simulated and measured parameters of the fire-generated environments are reviewed. While the computer code is found to provide generally favorable simulations for the entire range of tests, several areas of modeling detail are identified for further improvement.

\section{INTRODUCTION AND OBJECTIVE}

The NBS/Harvard VI fire simulator predicts the dynamic environment of fires in multi-room enclosures. Its computer code $[1,2]$ was an outgrowth of the Harvard $V$, single-room fire simulator [3,4]. Continued development of the code is being carried out at the Center for Fire Research of the US National Bureau of Standards [5].

The objective of the present work was to simulate with NBS/Harvard VI a series of full-scale multi-room fire tests [6] and to describe and analyze comparisons between the predictions and test data.

The extent to which a simulation and test data agree depends on the adaquacy of the simulation and the quality of the data. To thoroughly evaluate a simulation a number of different tests should be considered. Here comparisons with only one test series are made. A thorough assess. ment of Harvard VI would require consideration of a wider range of test data. Unfortunately, little other multi-room data is available.

\section{DESCRIPTION OF THE TESTS}

The test program is fully described in [6]. It involved either two or three rooms connected by open doorways; all had a $2.36 \mathrm{~m}$ ceiling height. The walls and ceilings were $0.013 \mathrm{~m}$ thick gypsum board, the floors concrete. The space was partitioned to yield four different

\footnotetext{
${ }^{*}$ Retired, Center for Fire Research, US National Bureau of Standards 
configurations ranging in total plan area from 40.6 to $89.6 \mathrm{~m}^{2}$, see Fig. 1. The door between the burn room and corridor was $2.0 \mathrm{~m} \mathrm{high}$ and $1.07 \mathrm{~m}$ wide. The door between the corridor and the next adjacent space (lobby) was $2.01 \mathrm{~m}$ high and $1.32 \mathrm{~m}$ wide. A $0.15 \mathrm{~m}$ high by $0.94 \mathrm{~m}$ wide hole next to the floor in a wall of the corridor provided the major path for mass exchange between the test space and the outside.

Each test used the same burn room of $14.0 \mathrm{~m}^{2}$ area. It contained a $0.3 \mathrm{~m}$ square methane diffusion burner in the center of the room. The burner surface was $0.24 \mathrm{~m}$ above the floor. Fuel supply was controlled manually to produce one of four energy release rates: a constant, $Q$, of $25 \mathrm{~kW}, 100 \mathrm{~kW}$, or $225 \mathrm{~kW}$ or a time varying energy release rate, $\mathrm{Q}_{\mathrm{ramp}}(t)$ $=30 \mathrm{t} \mathrm{kW}, 0<t<10 \mathrm{~min}$.

Free-burn characteristics of the burner used in these tests were studied in [7]. Using methane fuel and for fires between 50 and several hundred $\mathrm{kW}$ it was found that approximately 248 of the heat was radiated away from the combustion zone. For a $25 \mathrm{~kW}$ fire $19 \%$ was radiated.

As methane produced little smoke, a visual tracer of the combustion products was generated by a smoke candle and mixed with the fire's products of combustion in the ceiling jet of the burn room. Visualization of the upper smoke layers was achieved by placing fluorescent lights on the floor of the corridor and lobby.

For each of the four spatial configurations of Fig. 1 a separate test was run for each of the four energy release rates (16 tests). For the $100 \mathrm{~kW}$ fire and full corridor configuration three additional tests were run. In these the burn room-to-corridor doorway width was reduced to $1 / 2,1 / 4$ and $1 / 8$ of its full $1.07 \mathrm{~m}$ value.

Test instrumentation consisted of five thermocouple "trees" of eight thermocouples each located as shown by A-E in Fig. 1. Photometers measured the growth of the smoke layer and video tapes allowed post-test
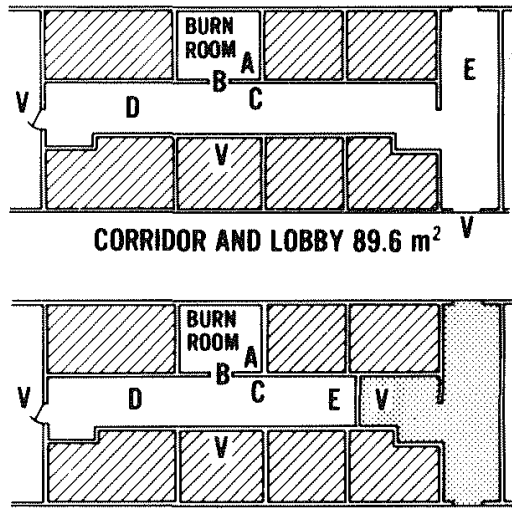

$3 / 4$ CORRIDOR $51.6 \mathrm{~m}^{2}$

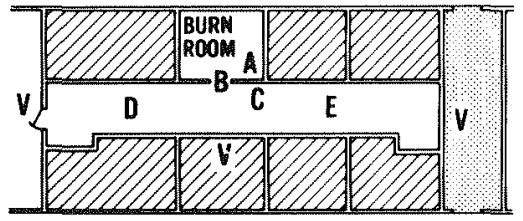

FULL CORRIDOR $62.4 \mathrm{~m}^{2}$

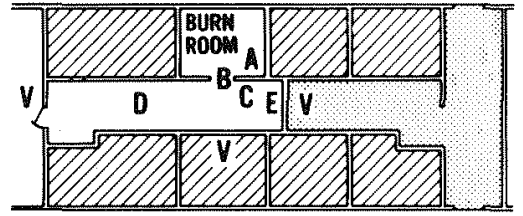

$1 / 2$ CORRIDOR $40.6 \mathrm{~m}^{2}$

Figure 1: Sketches of the four test configurations with indication of the locations of vertical instrument arrays ( $A, B, C, D$ and $E$ ) and of video cameras (V). 
analysis of the smoke layer growth by noting the extent of smoke obscuration of vertical scales mounted within the field of view of the cameras (at positions V of Fig. 1). A single pair of pressure taps located at ceiling level at $A$ and $C$ measured the pressure difference between the burn room and the corridor.

\section{TEST RESULTS AND THE PARAMETERS SIMULATED}

The NBS/Harvard VI code simulates the fire-generated environment within each room as having two homogeneous horizontal gas layers separated by a sharp interface: an elevated temperature, combustion-productladen upper layer and a lower layer of uncontaminated air at ambient temperature. Observations during fire tests suggest that this two-layer description is frequently reasonable. The approximation is idealized in that the actual interface between gas layers is not distinct. In some cases the transition region across which the gas temperature, smoke opacity and product of combustion densities change is relatively narrow, in others relatively broad. Further, in many fires, the gas in the lower part of the rooms is, at later times, neither free of smoke nor at ambient temperature $[6,8,9]$. Even where the transition is not distinct the two layer model may satisfactorily simulate the average upper and lower gas layer temperatures.

Reference [6] uses three rules for defining a layer interface height based on experimental data: (1) the height at which the gas temperature rise above ambient is $N$ percent of the temperature rise at the topmost thermocouple or at least $0.5 \mathrm{~K}$; (2) an analogous rule applied to the photometer data; and (3) visual observation as determined from video tapes. Tabulated interface heights according to rules 1 and 2 for $N=10$ and to rule 3 are provided in [6] for each room during all nineteen tests.

Reference [6] presents vertical temperature distributions for only one of the nineteen tests and for this at only one corridor thermocouple tree location and at only one time. In general, three time-varying measures of the thermocouple tree data are presented for each room during all tests. The first of these is the floor-to-ceiling-averaged temperature. The second is the interface elevation according to rule 1 with $\mathrm{N}=10$. The third is a result of analysis of the first of these measures and leads to estimates of the instantaneous total rates of heat transfer to bounding surfaces of the test space (given in terms of a fraction, $\lambda$, of the instantaneous burner power). $\lambda(t)$ is estimated from the $\Delta T(t)$ data and $Q(t)$ according to Eqs. (4) and (5) of [6]. To simplify comparisons the simulation results are expressed in the same form as the data in [6].

\section{COMPARISONS BETWEEN SIMULATION AND EXPERIMENT}

Five types of comparisons between NBS/Harvard VI simulations and the experimental data are presented in this paper:

(1) Predicted two-layer interface elevations and experimentally determined $N=10$ elevations.

(2) Time-varying rate of total heat transfer to the bounding surfaces of the multi-room configuration as represented by $\lambda$.

(3) Pressure difference between the burn-room and corridor at ceiling leve1. 
(4) Floor-to-celling averaged temperatures.

(5) Vertical distribution temperature data (using previously unpublished experimental data from these tests.)

Simulations were carried out for all 19 tests and are fully reported in [17]. Representative comparisons are presented here.

Input data for the computer runs are presented in Table 1.

\section{PRESENTATION OF THE TEST DATA AND THE PREDICTIONS}

Computed results and corresponding experimental data for the interface elevations in each of the three rooms are plotted in Fig. 2 a for the $100 \mathrm{~kW}$ fire, standard door, burn-room, corridor and lobby configuration. In Fig. $2 b$ are the computed and measured: (1) heat transfer parameter, $\lambda$; (2) burn-room-to-corridor cross-doowway, ceiling level pressure differential, $\Delta \mathrm{p}$, and (3) vertically-averaged temperature rise histories based on thermocouple tree data at locations $A, D$ and $E$ as noted on Fig. 1 .

Plots similar to Fig. 2 are provided in Fig. 3 for one other test. Discussion of these results is presented next along with results of additional simulations.

Fig. 4 presents the predicted and measured vertical temperature distributions in the three rooms for a $100 \mathrm{~kW}$ fire at 200 seconds.

\section{DISCUSSION OF RESULTS AND ADDITIONAL SIMULATIONS}

Fig. $2 b$ and $3 b$ show the vertically averaged temperature rise for two different fire sizes and compartment volumes. The most striking feature observed on comparing these figures is the distinct break in the computed temperature rise for the larger fire in the smaller space which is not reproduced in the data, Fig. $3 \mathrm{~b}$. This is due to inadequate modeling of "oxygen-limited burning". The simulation always models the upper layer gas as being so depleted of oxygen that it will not support combustion. For the cases considered here and, indeed, for many other scenarios the assumption is overly restrictive. This defect in the simulation should be corrected.

In a number of cases the predicted temperature rose faster at the beginning of the test than the experimental data (Fig. 2). This was by no means always the case, however. Taken together the results suggest that manual adjustment of the gas flow to the burner may not have produced the same build-up to steady gas flow rate as assumed in the calculation.

The gas burner algorithm does not directly account for the heat needed to bring the burner itself to operating temperature. If the algorithm were improved in this respect the predicted temperature would rise more slowly than it now does. This would improve agreement with most of the tests but make it less satisfactory for othexs.

Besides the above, two distance trends appear when comparing the simulation results with the experimental data. One is observed as fire size varied, the other as the burn room door size varied. 

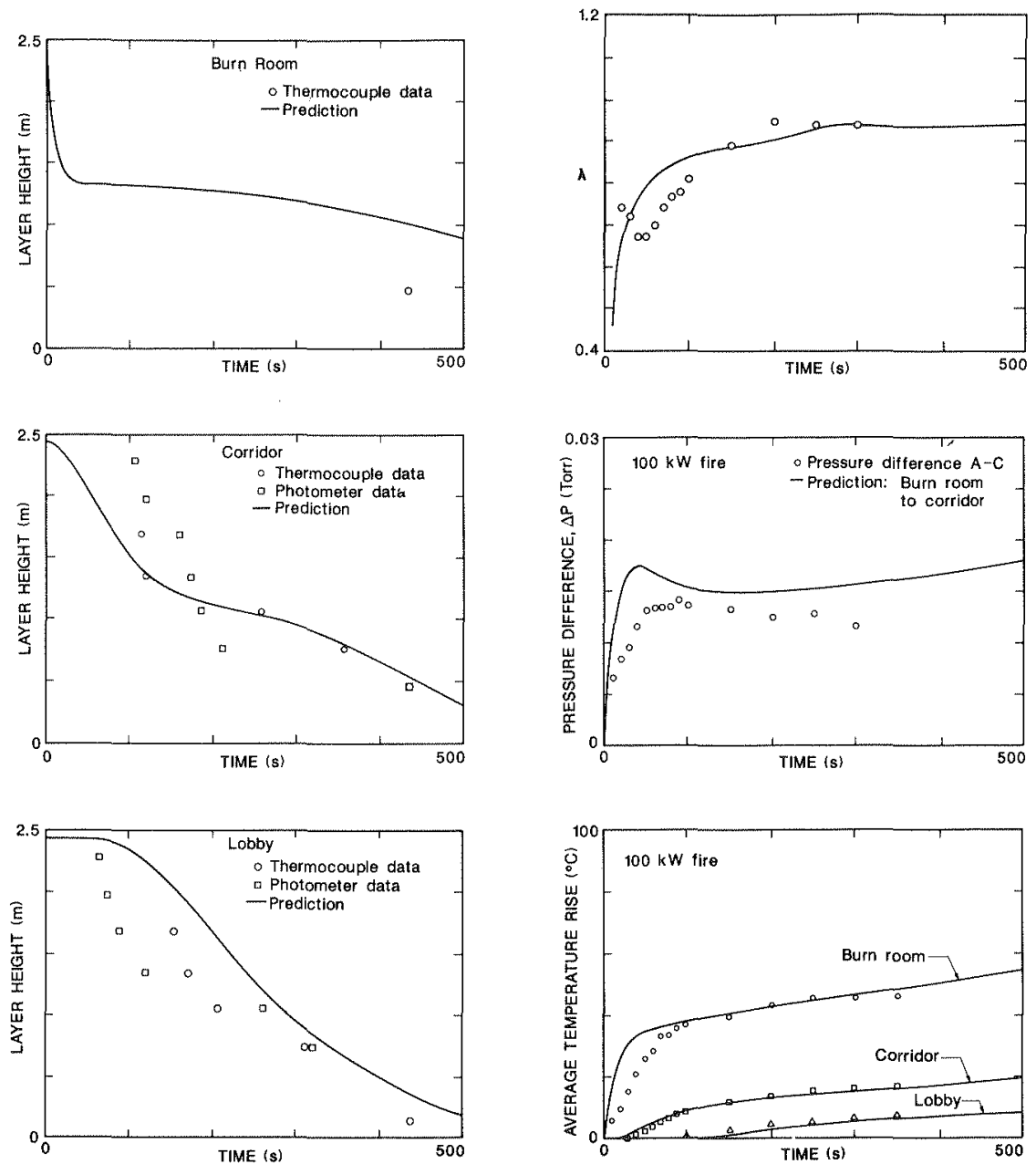

Figure 2a: $100 \mathrm{~kW}$ fire, Corridor and Lobby configuration: Layer heights.

Figure 2b: $100 \mathrm{~kW}$ fire, Corridor and Lobby configuration: , pressure difference and average temperature rises.

As for the first trend, the simulation often predicts higher-than measured burn room temperatures for the larger fires and smaller ones for the smaller fires. The reverse tendency may be present in the corridor and lobby although the temperature rise is so small in these spaces that this is somewhat less obvious. For the ramp fires the prediction lies consistently above the experimental data for all times.

The $\lambda$ plots indicate no consistent trend in comparisons of measured and predicted heat loss to the boundary surfaces. For these there is general agreement between the experiments and simulations after an 

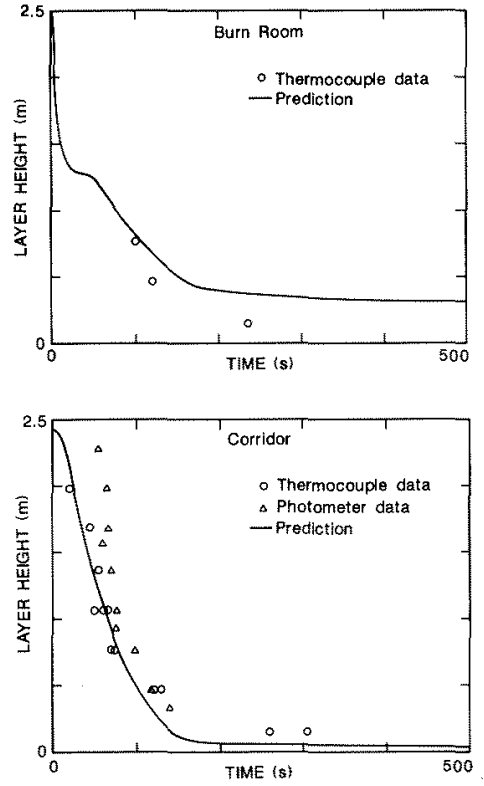

Figure 3a: $225 \mathrm{~kW}$ fire, $1 / 2$ Corridor configuration: Layer heights

Figure 3b: $225 \mathrm{~kW}$ fire, $1 / 2$ Corridor configuration: , pressure difference and average temperature.

Both: Open symbols, experiment; line simulation
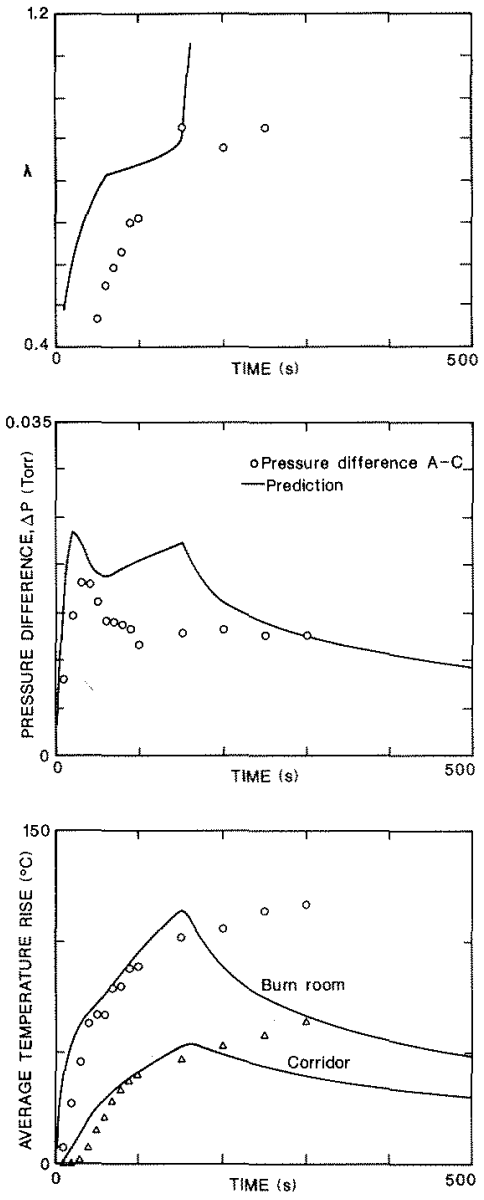

initial period. The $\lambda$ calculation is for heat losses throughout the entire space. Thus, for any given test, good agreement between measured and predicted values of $\lambda$ could be obtained if predicted losses were over-estimated in the burn room and under-estimated in other spaces. Were it not for the ramp fires where the trend is uneven, the $\lambda$ plots together with the average temperature rise plots suggest that the simulation heat transfer is under-estimated for the highei temperatures and over-estimated for the lower ones. In assessing simulation versus experimental $\lambda$ values, note that the experimental values are based on temperatures at only one location in each of the rooms. This may limit the accuracy of the measurement derived values of $\lambda$. On the other hand many approxima-tions are embedded in the $\lambda$ estimate of the simulation and these may limit its accuracy. Where the simulation predicts oxygenlimited burning (see figure 3 ) the fall in gas temperature causes stored heat to flow from the walls and ceiling to the gas. This makes $\lambda$ increase. If enough heat is transfered from the walls, $\lambda$ can exceed 1 . 
The second trend appears in the four $100 \mathrm{~kW}$ full corridor tests in which the burn-room door size was varied. The simulation under-estimated the burn room temperature for the smallest door with improving agreement as the door size increased. There are three possible reasons for this discrepancy. First, the simulation does not include the effect of mixing between the hot gas exiting from the room and cool gas entering via the same vent. It has been shown that this can be important [8] and, when modeled [9], raises the gas temperature in the burn room and thins the upper layer. The effect would be more pronounced for the smaller doors. Second, the data suggests that the simulation predicts too much flow exiting from the narrower doors. Note, however, that the data for steady gas burner fires in a room with various openings [10] was well modeled by the same door flow algorithm used here [9]. Thirdly, better simulation results might be obtained from a convective heat transfer algorithm which more accurately averaged the variation of heat transfer coefficient from peak values at plume-ceiling impingement to relatively low values at distant ceiling and upper wall surface elements [11-14].

Figure 4 presents typical vertical temperature profiles together with the corresponding simulation result. For the burn room, the experimental data clearly show two nearly isothermal gas layers separated by a roughly $20 \mathrm{~cm}$ thick transition region. The predicted layer depth is in satisfactory agreement with the data. Note that there is some increase in the lower layer temperature above ambient. For the case of the $100 \mathrm{~kW}$ fire where the measured and predicted average temperature rise are in good agreement this agreement is obtained from a predicted upper layer temperature which is too high combined with a lower layer temperature which is too low. Were mixing at the vent included, the lower layer
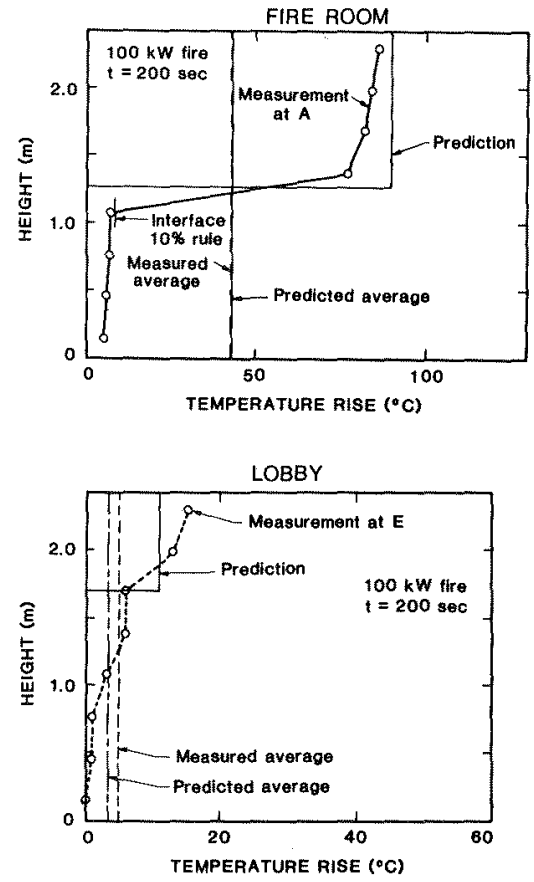

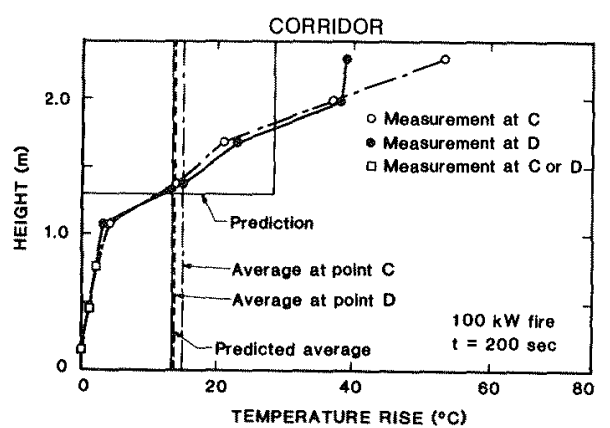

Figure 4: Vertical temperature profiles, $100 \mathrm{~kW}$ fire, Corridor and Lobby configuration at $200 \mathrm{sec}$. 
temperature would rise due to the effects of mixing. Also the predicted upper layer temperature would rise somewhat due to decreased radiation heat loss through the lower layer to the floor. Thinning of the upper layer would result in less increase of the average gas temperature than would otherwise be expected.

While the two layer model seems satisfactory for the burn room the vertical temperature data for the corridor and lobby (Fig. 4) show that, away from the burn room, the assumption of two distinct isothermal gas layers is much more questionable. The two layer model is based on the assumption of well mixed layers. In reality formation of the hot layer in rooms other than the burn-room may take considerable time $[15,16]$. For times allowing only the initial filling process to occur, a pair of wel1 mixed layers may not be produced. Thus, it is not to be expected that the two-isothermal-layer model, based as it is on the assumption of well mixed layers formed rapidly in comparison to the total simulation time, would be entirely satisfactory for the corridor and lobby for the test times studied here. For these a more detailed transient model of layer growth may be desirable. Even so, as will be elaborated in the next paragraph, the two-layer model seems to give adequate overall predictions for the average temperature and layer depth in these spaces.

Turning now to the layer depth comparisons (Fig. $2 a$, and $3 a$ ) the computed layer interface heights are seen to be generally higher than those given by applying the 10 percent temperature rise rule to the experimental data. Where the temperature data suggests a more rapid fire build-up for the calculation than the actual fire, the computed layer descends more rapidly than the data indicates. This is to be expected if the computed and actual fires do not develop in the same way. Considering the scatter of the experimental layer depth data the results are satisfactory. They do, however, suggest use of either a layer interface definition by the "N percent rule" [6] with $\mathrm{N}$ greater than 108 .

The use of artificial smoke to allow the hot layer behavior to be tracked was not simulated in the calculations and may have influenced the comparisons. This would be expected to have more influence on the configurations producing higher upper layer temperatures than those where upper layer temperatures were lower. (Note, no test was re-run without artificial smoke to assess its effect.) The simulation can treat gas as we11 as particulate radiation and, with empirically altered input data to account for the artificial smoke, it might have produced more favorable comparisons. However, empirical adjustment of input to produce a "best fit" to experimental data must be used with caution when assessing the capability of a model. This was not done here.

\section{CONCLUSIONS}

The most important conclusion from this study is that the NBS/ Harvard VI multi-room fire model can provide useful predictions of fire generated environments in multi-room scenarios similar to those studied experimentally in [6]. These can be characterized by fire sizes on the order of several hundred $\mathrm{kW}$ and total compartment areas of the order of $100 \mathrm{~m}^{2}$.

As the compartment geometry or fire size varied the trends found experimentally were reproduced by the simulations. There were differences in deta11. In some cases the experimental data and simulations 
differed in ways that are most likely due to differences between the assumed and actual, but undocumented experimental conditions.

The simulation's modeling of "oxygen-limited burning" caused problems in simulating the larger fires in the smaller spaces. Revised physics to account more properly for burning when the hot gas layer reaches or even envelopes a burning object should be included.

Mixing of the hot and cool layer gases as they pass through a vent should be included in the simulation. Mixing occurs on both sides of a vent and both should be included. This might improve agreement between the experimental data and the predictions, especially in the partially open burn-room-door cases.

More detailed modeling of convective heat transfer could lead to improvements in all aspects of temperature predictions. This is especially true for fire scenarios, like the ones studied here, where temperature increases of the upper layers are not so high that radiation dominates the heat transfer.

Improvement of the gas burner algorithm to account more accurately for the heat absorbed by the burner body early in the fire is worth considering.

\section{REFERENCES}

[1] Gahm, J B, "Computer Fire Code VI", NBS-GCR-83-4451 (2 volumes), US Nat Bur of Stds, Gaithersburg, MD 20899, 1983.

[2] Ramsdel1, J, "Variable Elimination in the Home Fire Code", ASME/ AIChE Heat Trans Conf, paper 81-HT-3, Milwaukee, WI, Aug, 1981.

[3] Mitler, H, "The Physical Basis for the Harvard Computer Fire Code", Home Fire Project Tech Rpt No 34, Div of App Sc, Harvard Univ, Cambridge MA, Oct 1978.

[4] Mitler, $\mathrm{H}$ and Emmons, $\mathrm{H} W$, "Documentation for CFC V, The Fifth Harvard Computer Fire Code", Home Fire Project Tech Rpt No 45, Div of App Sc, Harvard Univ, Cambridge MA Oct 1981.

[5] Rockett $J A$ and Morita, M, "The NBS/Harvard VI Multi-room Fire Simulation", Fire Sc and Tech, Vol 5, No 2, pp 159-164, 1985.

[6] Cooper, L Y, Harkleroad, M, Quintiere, J $G$ and Rinkinen, W, "An Experimental Study of Upper Hot Layer Stratification in Full-Scale Multiroom Fire Scenarios", J, of Heat Trans, Vol 104 pp 741-749, 1982.

[7] McCaffrey, B J, "Measurements of the Radiative Power Output of some Buoyant Diffusion Flames", Western States Section, Comb Inst, WSS/CI $81-15$, Pu1lman WA, 1981.

[8] McCaffrey, B J and Rockett, J A, "Static Pressure Measurements of Enclosure Fires", Jour of Res of the Nat Bur of Stds, Vol 82, No 2, pp 107-117, 1977 .

[9] Rockett, J A, "Modeling of NBS Mattress Tests with the Harvard Mark V Fire Simulation", Fire and Mat, Vol 6, No 2, pp 80-95, 1982.

[10] Steckler, K D, Quintiere $J G$ and Rinkinen, $W$, "Flow Induced by Fire in a Compartment", NBSIR 82-2520, US Nat Bur of Stds, Gaithersburg MD 20899, Sept 1982 .

[11] Alpert, R L, "Fire Induced Turbulent Ceiling-Jet", FMRC Serial No 19722-2 May 1971. Factory Mutual Res Corp, 1151 Boston-Providence Tpk, Norwood MA 02062 . 
[12] Veldman, C G, Kubota T and Zukoski E E, "An Experimental Investigation of the Heat Transfer from a Buoyant Gas Plume to a Horizontal Ceiling - Part 1, NBS-GCR-77-97, Part 2, NBS-GCR-77-98, US Nat Bur of Std, Gaithersburg MD 20899, 1977.

[13] Cooper, L Y, "Heat Transfer from a Buoyant Plume to an Unconfined Ceiling", Jour of Heat Trans, Vo1 104, pp 446-451, 1982.

[14] Cooper, L Y and Stroup, D, "Thermal Response of Unconfined Ceilings Above Growing Fires and the Importance of Convective Heat Transfer", Jour of Heat Trans, Vol 109, pp 172-178, 1987.

[15] Tangren, E N, Sargent, $\mathrm{W} J$ and Zukoski E E, "Hydraulic and Numeric Modeling of Room Fires", Daniel and Florence Guggenheim Jet Propulsion Center, Cal Inst of Tech, Pasadena CA, June 1978.

[16] Zukoski, E E and Kubota, T, "Experimental Study of Environment and Heat Transfer in a Room Fire, Final Report", Gal Inst of Tech, Div of Eng and App Sc, Pasadena CA, July 1984.

[17] Rockett, J A, Morita, M and Cooper, I Y, "Comparisons of NBS/Harvard VI Simulations and Ful1-Scale Multi-room Fire Test Data", NBSIR 87 3567, US Nat Bur of Stds, Gaithersburg MD 20899, 1987.

\section{TABLE 1}

Simulation Input Data

Fuel Properties:

Heat of Combustion

Fraction of heat released

55.5

0.99

17.25

Gr $\mathrm{CO}_{2}$ produced per gr fuel burned 2.75

Gr 120 produced per gr fuel burned 2.25

Gr CO produced per gr fuel burned 0.019

Gr soot produced per gr fuel burned 0.008

Flame absorption coefficient 1.55

Thermal Properties of Walls:

\section{Thickness}

Density

Specific heat

Thermal conductivity

$\begin{array}{cl}0.0254 & \mathrm{~m} \\ 800 . & \mathrm{kg} / \mathrm{m}^{3} \\ 1062 . & \mathrm{J} / \mathrm{kg}-\operatorname{deg~C} \\ 0.134 & \mathrm{~W} / \mathrm{m}-\operatorname{deg~C}\end{array}$

Room Dimensions:

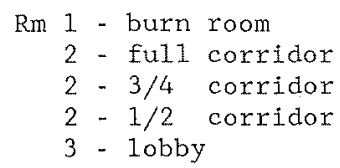

$4.22 \times 3.35 \times 2.44 \mathrm{high}$

$18.97 \times 2.41 \times 2.44$

$14.23 \times 2.41 \times 2.44$

$9.48 \times 2.41 \times 2.44$

$3.00 \times 15.40 \times 2.44$

Vent Geometries:

$\begin{array}{rcccc}\mathrm{Rm} & 1-\mathrm{Rm} 2 & 1.07 \times 2.03 & \text { high } & (\mathrm{fu} 11 \text { door }) \\ 1 & 2 & 0.54 \times 2.03 & (1 / 2 & \text { door }) \\ 1 & 2 & 0.27 \times 2.03 & (1 / 4 \text { door }) \\ 1 & 2 & 0.13 \times 2.03 & (1 / 8 \text { door }) \\ 2 & 3 & 1.25 \times 2.01 & & \\ 2 & - \text { outside } & 0.94 \times 0.15 & & \end{array}$

